\title{
In silico study of COX-2 on indomethacin and diclofenac as nonsteroidal anti-inflammatory drugs (NSAIDs)
}

\author{
Janatun Na'imah ${ }^{[1]^{*}}$ \\ 1 Program Studi DIII Farmasi, STIKES Delima, Gresik, Indonesia \\ Email: janatunna39imah@ymail.com Telp: (+62) 821-4100-5503
}

\begin{abstract}
ARTICLE INFO
ABSTRACT

Article History

Received March 1, 2019

Revised March 27, 2019

Accepted April 1, 2019

Keywords

COX-2

Indomethacin

Diclofenac

Molecullar docking

Doi

10.22219/farmasains.v4i1.7767

Cyclooxygenase is an enzyme that plays a role in the formation of prostaglandins, which can cause inflammation and pain when overexpressed. This study aims to determine the interaction between COX-2 macromolecules (receptors) with their ligands, namely indomethacin and diclofenac in silico using the Molecular Docking method. The COX-2 receptor was downloaded in the form of a 3D structure from the RCSB GDP with code 5F19. Diclofenac Ligand and Indomethacin were downloaded in the form of a 3D structure from the RCSB GDP with $4 Z B Q$ code and 4IK7 code. The results showed that the interaction between COX-2 and indomethacin was the interaction of hydrogen, which linked indomethacin with amino acid Leu531 and steric interactions between indomethacin and amino acids Trp387, Tyr385, Tyr355, Leu352, and Val523. The interaction of [COX-2 - Indomethacin] produces a value of $\Delta G$ of $-103.136 \mathrm{kcal} / \mathrm{mol}$, and the value of RMSD is $1.244 \AA$. Whereas, the interaction that occurs in COX-2 with diclofenac is the steric interaction that happens between diclofenac with amino acids Leu390, Trp387, GIn203, His388, His207, and Thr206. The interaction parameter between [COX-2Diclofenac] obtained $\Delta G$ value of $-7.843 \mathrm{kcal} / \mathrm{mol}$ and an RMSD value of $2.07851 \AA$ A.
\end{abstract}

How to cite: Na'imah, J. (2019). In silico study of COX-2 on indomethacin and diclofenac as nonsteroidal antiinflammatory drugs (NSAIDs). Farmasains : Jurnal Farmasi dan IImu Kesehatan, 4(1), 31-36. Doi: https://doi.org/10.22219/farmasains.v4i1.7767.

\section{INTRODUCTION}

Inflammation is a complex that occurs through several mechanisms that cause changes in the bloodstream and the release of several inflammatory mediators, which is causes vasodilation, increased vascular permissiveness, and leukocyte migration to the site of inflammation. Inflammation is an attempt to eliminate triggers for injuries (such as infections) and to initiate the process of wound healing. There are five main signs or cardinal signs that generally appear during inflammation, namely pain, heat, redness, swelling, and loss of function. The occurrence of warmth and redness is caused by increased blood flow, swelling caused by the accumulation of fluid, pain by the release of various compounds that stimulate the pain nerves, and loss of function for multiple reasons (Chandrasoma and Taylor, 2005).

Cyclooxygenase (COX) is one of the main enzymes that play a role in inflammation. Cyclooxygenase is 
an enzyme that plays a role in the formation of prostaglandins-prostaglandins, which can cause inflammation and pain when overexpressed. COX has two isoforms, namely COX-1 and COX-2 isoenzymes. COX-1 is composed of 576 amino acids, while COX-2 is composed of 581 amino acids. COX has two isoforms, namely COX-1 and COX-2 isoenzymes. COX-1 is composed of 576 amino acids and has three oligosaccharides, one of which oligosaccharides play a role in protein folding. COX-2 is composed of 581 amino acids and has four oligosaccharides, where one oligosaccharide plays a role in folding proteins, and the fourth oligosaccharide plays a role in the degradation of this protein (Rouzer and Marnett, 2009).

COX-1 is produced by most types of cells in the body. The COX-1 gene is called Ptgs- 1 . This gene encodes a stable $2.8 \mathrm{~kb}$ RNA mRNA. The genes for COX-2, Ptgs2 , are activated, especially when there is the stimulation of inflammatory mediators or bacterial endotoxins in the tissues. This gene, if activated, will produce a $4 \mathrm{~kb}$ mRNA that is easily damaged due to instability in the 3 '-untranslated region. COX-2 is unique because it has a higher sensitivity to hydroperoxide than COX-1 so that it can work at lower arachidonic acid concentrations than COX-1 (Rouzer and Marnett, 2009). Also, COX-2 is expressed after induction in the form of an inflammatory environment, which raises the hypothesis that COX-1 works for homeostasis while COX-2 works in pathological processes (Serhan and Oliw, 2001).

COX-1 and COX-2 play a role in the biosynthesis of prostanoids from their substrate, namely arachidonic acid via the arachidonic pathway. Prostanoids are active mediator chemicals produced from COX work. Prostanoids are part of eicosanoids, which are a large group of biochemical compounds, which include thromboxane, prostacyclin, leukotriene, hydroxyeicosatetraenoic acid, epoxyeicosatrienic acids, lipoxins, and isoprostane. Each eicosanoid class has a specific function and works locally to regulate individual cell responses (Serhan and Oliw, 2001).

NSAIDs (Nonsteroidal Anti-inflammatory Drugs) are drugs that are used as strong analgesics, antiinflammatory, and antipyretic drugs, but can cause gastrointestinal side effects. The group of NSAIDs includes aspirin, non-selective cyclooxygenase (COX) inhibitors, and selective COX-2 inhibitors that have general abilities as analgesics, anti-inflammatory, and antipyretic. NSAIDs can be grouped into several classes according to their basic chemical structure, namely the classes of acetic acid, oxicam, propionic acid, salicylate, and coxib (McDonald, 2016).

Some drugs included in NSAIDs are diclofenac and indomethacin. Diclofenac is a phenylacetic acid derivative compound that can reduce the risk of gastrointestinal injury but can cause diarrhea when combined with misoprostol. Indomethacin is a nonselective COX inhibitor and is also able to inhibit phospholipase $A$ and $C$, inhibit neutrophil migration, and reduce $T$ cell and $B$ cell proliferation. It is now expected that the selection of drugs with high selectivity to specific receptors to obtain the maximum therapeutic effect. Therefore, to understand the mechanism of action and the effects of NSAIDs (i.e., diclofenac and indomethacin) on the body, we need to have an understanding of what processes are inhibited by the drug namely the COX enzyme and the arachidonic pathway where the enzyme works.

The method used is Molecular Docking, which is a molecular modeling method that is used as a scientific justification or predicts the biological activity of a compound in silico. The receptors used were COX-2 receptor proteins obtained from the RCSB Protein Data Bank. The ligands used were diophase and indomethacin, which were also obtained from the RCSB Protein Data Bank.

\section{RESEARCH METHOD}

\section{Tools}

The equipment used in this study has specifications Intel (R) Core (TM) i3 M330 2.13GHz CPU with 2.00GB RAM. Software used in this study included HyperChem, Molegro Molecular Viewer (MMV), PatchDock, PyMOL, Poseview, and Accelrys Discovery Studio 3.5.

\section{Material}

The materials used in this study included COX-2 receptors (code 5F19), diclofenac ligands (code 4ZBQ), and indomethacin ligands (code 4IK7).

\section{Methods}

\section{Preparation of Macromolecules}

In this study, the macromolecules used were COX-2, which was downloaded in the form of an amino acid sequence from the RCSB Protein Data Bank. These macromolecules are downloaded and stored in a conformer 3D form. Then, optimization is done using PyMOL so that the most stable geometry structure can be obtained. The results are stored in a format 
(.pdb), which is then used in the docking process with Molegro Molecular Viewer (MMV) and PatchDock.

\section{Preparation of Ligands}

The ligands used were indomethacin and diclofenac downloaded from RCSB Protein Data Bank. Ligands are downloaded and stored in a 3D conformer form, and if a $3 D$ conformer is not available, it can be downloaded and stored in the 2D structure. The downloaded ligands are in the form of file format (.sdf), then converted into format (.hin) using open babel. Then, optimization is done using PyMOL so that the most stable geometry structure can be obtained. The results of the ligand optimization are stored in the format (.mol) and (.pdb) used for the next process, namely docking. Ligands downloaded and stored in the form of 2D structures, will be processed into 3D conformers in the following way: Hydrogens and build models are added to the geometric structure using PyMOL after the file format has been changed to (.hin). After that, optimization is carried out, and the most stable geometry structure will be obtained. The ligand optimization results are stored in the format (.mol) and (.pdb).

\section{Docking Process}

In this study, two docking stages were carried out, namely COX-2 with diclofenac and COX-2 with indomethacin. The initial stages carried out before the docking process was the optimization of COX-2 macromolecules and diclofenac and indometachin ligands using PyMol. Furthermore, a docking process is carried out using MMV and PatchDock, so that binding energy values, Root Mean Square Deviation (RMSD), attractive $\mathrm{VdW}$ and repulsive $\mathrm{VdW}$ are obtained. The docking results were analyzed using Poseview so that the active site of the COX-2 amino acid was known to interact with the indomethacin and diclofenac ligands, the interactions that occurred, and the RMSD value.

\section{RESULTS AND DISCUSSION}

Cyclooxygenase (COX) is one of the main enzymes that play a role in inflammation. COX has two active sites, namely the active side of cyclooxygenase and the active side of peroxidase (Rouzer and Marnett, 2009). The active side of cyclooxygenase is located in the hydrophobic area, i.e., on the L-shaped canal peak. The substrate or inhibitor must enter this channel to reach the active site of cyclooxygenase (Rouzer and Marnett, 2003). In a position opposite the hydrophobic area of cyclooxygenase, there is an active side of peroxidase that resembles a valley with a basic heme group and a hydrophobic amino acid hill around the valley (Kulmacz, van der Donk \& Tsai, 2003).

COX-2 is the primary isoenzyme in the inflammatory process, where COX-2 plays a role in the blockade of arachidonic acid (prostaglandin) metabolites, which has the effect of reducing pain and fever in patients with rheumatoid and gout. Arachidonic acid is a polyunsaturated fatty acid with $20 \mathrm{C}$ atoms consisting of four double bonds, mainly derived from linoleic acid (especially in the form of esters as a component of cell membrane phospholipids). Amino acids are released from phospholipids through cell phospholipases, which have been activated by mechanical, chemical, or physical stimuli such as inflammatory mediators such as C5a (anaphylatoxin) (Kumar, Coltran \& Robbins, 2012).

The arachidonic acid metabolism process occurs through one or two main pathways, namely cyclooxygenase (synthesizing prostaglandin and thromboxane) and lipoxygenase (synthesizing leukotrienes and lipoxins). In the cyclooxygenase pathway, several products are produced, such as prostaglandin PGE2, PGD2, PGF2 $\alpha, \quad$ PGI2 (prostacyclin), and thromboxane A2 (TXA2). Each of these products is provided by a specific enzyme and has a limited network distribution.

Molecular Docking is a method to determine the interaction between COX-2 macromolecules with indomethacin and diclofenac ligands in silico. COX-2 macromolecules are downloaded in the form of a 3D structure of RCSB GDP with 5F19 code. Diclofenac and indomethacin ligands are downloaded in the form of a 3D structure of the RCSB GDP with the 4ZBQ code and 4IK7 code. COX-2, diclofenac, and indomethacin conformation were optimized using PyMOL so that conformation with the most stable geometric structure can be obtained, and then the docking process was carried out with MMV and Patch Dock.

In this study, two docking processes were carried out between the COX-2 receptor against indomethacin and diclofenac ligands. The first docking process was carried out using MMV so that some parameters such as amino acids from COX-2 (active site), $\Delta \mathrm{G}$, and RMSD were obtained. The second docking process was done using PatchDock, and the resulting $\Delta G$, attractive $\mathrm{VdW}$, and repulsive $\mathrm{VdW}$ parameters were generated. $\Delta G$ shows the amount of energy needed between the receptor and the ligand to bind. RMSD shows the position of the copy ligand similar to the 

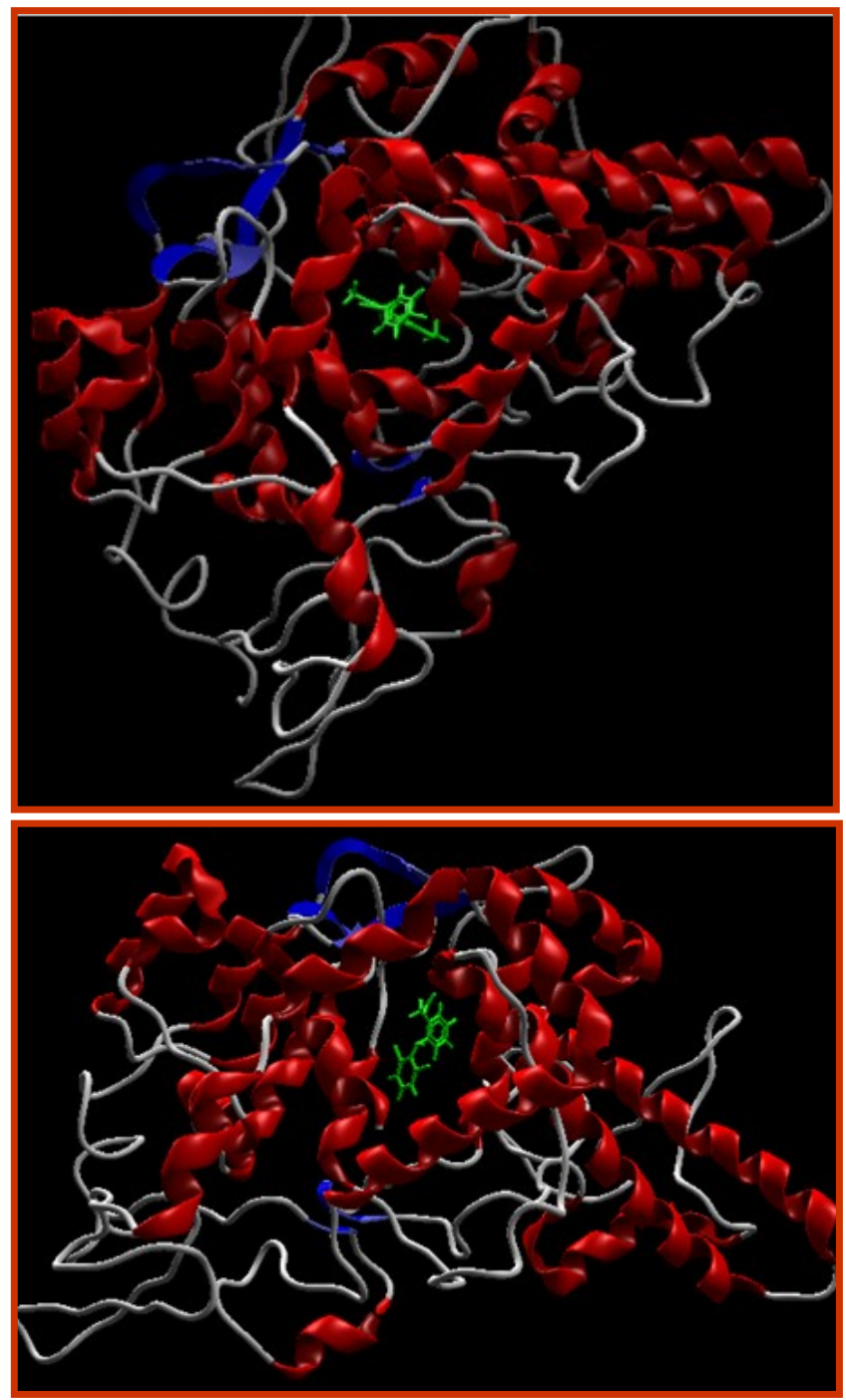

Figure 1. 3D visualization of COX-2 receptors with indomethacin (top) and diclofenac (bottom) ligands

native ligand.

The interaction between proteins and ligands aims to determine the types of amino acids found in the active sites of COX- 2 receptors, which then interact with ligand compounds. The first docking analysis between COX-2 receptors againts indomethacin and diclofenac ligands was carried out using MMV. The interactions that occur between COX-2 and indomethacin are the steric interactions and interactions of hydrogen. Hydrogen interactions connect between indomethacin and the amino acid Leu 531. Steric interactions connect between indomethacin and Trp 387, Tyr 385, Tyr 355, Leu 352, and Val 523 (Figure 2). Indomethacin compounds interact with six amino acid residues from the COX-2 receptor so that it can be predicted
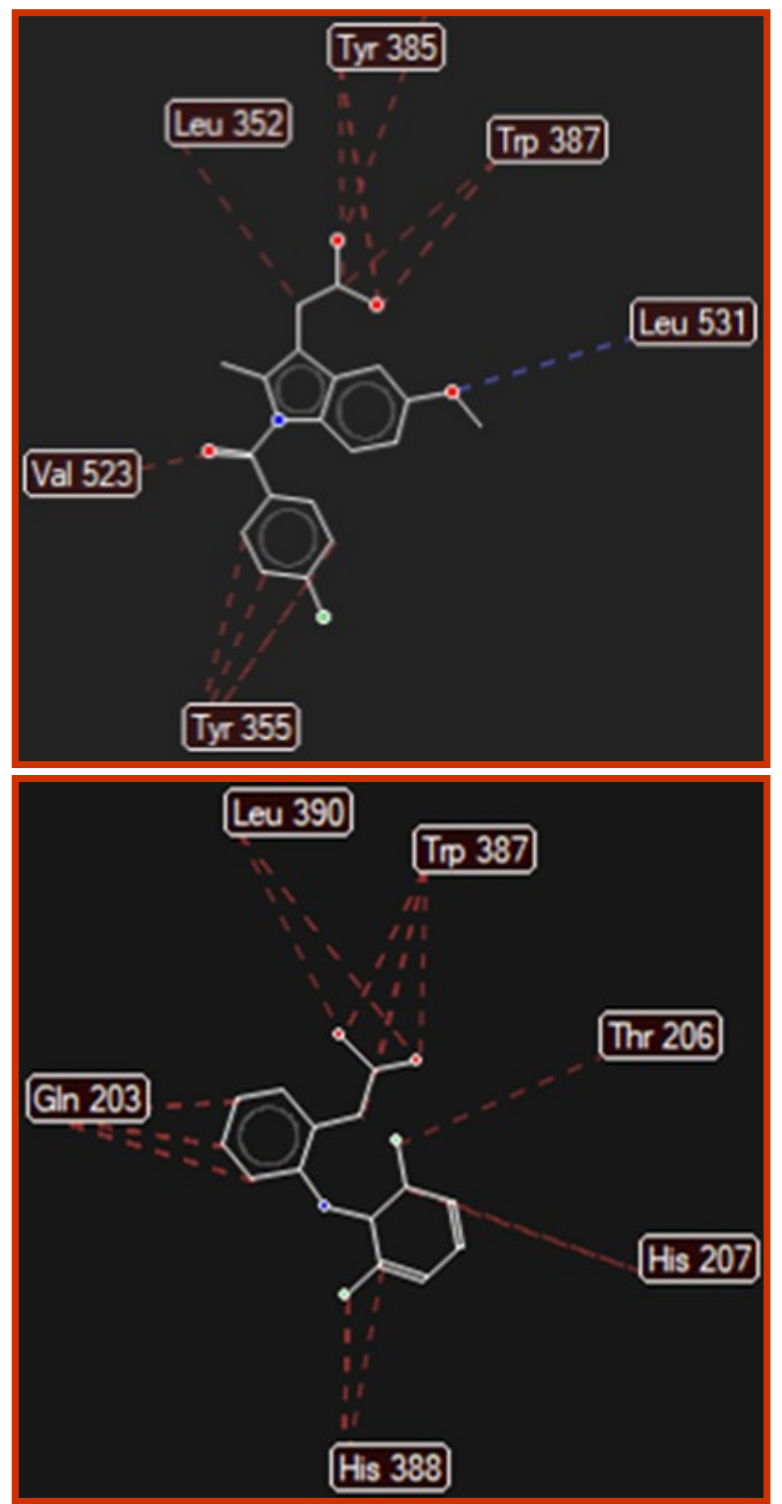

Figure 2. 2D visualization of COX-2 receptors with indomethacin (top) and diclofenac acid (bottom) ligands. Red dashed line showed hydrogend bond and blue dashed line showed steric interaction.

that indomethacin can inhibit COX-2, which causes disruption of conversion of arachidonate to prostaglandin (PGG2).

Steric interactions are interactions that occur due to the release of related energy caused by overlapping cloud electrons. This is because atoms are close together in a molecule. The results of the interaction between COX-2 and indomethacin obtained $\Delta G$ value of $-103.136 \mathrm{kcal} / \mathrm{mol}$ and an RMSD value of $1.244 \AA$. If the RMSD value is $\leq 2$, the copy ligand position is similar to native ligand, so a valid docking method is used to predict COX-2 interactions with indomethacin. Also, several parameters were obtained using PatchDock, namely $\Delta G$ value of $-42.71 \mathrm{kcal} / \mathrm{mol}$, attractive $\mathrm{VdW}$ of -17.90 , and repulsive $\mathrm{VdW}$ of 3.21 . 
NSAIDs can inhibit the cyclooxygenase enzyme so that the conversion of arachidonic enzymes to PGG2 is disrupted, such as indomethacin and diclofenac. Each drug inhibits cyclooxygenase with different strengths and selectivities. Indomethacin is an indole derivative compound that can inhibit non-selective COX, which is usually used for the treatment of rheumatoid arthritis and the like. Indomethacin is effective, but its use is limited because it is toxic. Indomethacin has anti-inflammatory and analgesicantipyretic effects, which are roughly comparable to aspirin. Indomethacin has peripheral and central analgesic effects (such as colchicine) and can inhibit polymorphonuclear leukocyte motility. The process of inflammation can result in vascular changes, namely changes in blood vessel capillaries that increase blood flow (vasodilation) and structural changes that allow plasma proteins to leave the circulation (increased vascular permeability) and various events that occur in cells, the emigration of leukocytes from microcirculation. Its accumulation is focused on networking (recruitment and cellular activation). A series of events in acute inflammation are integrated by the local release of chemical mediators. Vascular changes and cell recruitment determine three of the five classic local signs of acute inflammation, namely heat (heat), red (rubor), and swelling (tumor) (Kumar, Coltran \& Robbins, 2012).

Indomethacin absorption after oral administration 92-99\% will be bound to plasma proteins. Indomethacin side effects are dose-dependent, and the incidence is quite high. At therapeutic doses, one -third of patients discontinued treatment because of side effects. Gastrointestinal side effects include abdominal pain, diarrhea, gastric bleeding, and pancreatitis. The usual indomethacin dose is 2-4 times $25 \mathrm{mg}$ daily to reduce rheumatic symptoms at night indomethacin is given $50-100 \mathrm{mg}$ before bedtime (Wilmana and Gunawan, 2012).

Diclofenac is a simple derivative of phenylacetate acid, which is the most active anti-inflammatory NSAIDs with lighter side effects than other NSAIDs such as indomethacin and piroxicam. Diclofenac has analgesic, antipyretic, anti-inflammatory activity and functions as a cyclooxygenase inhibitor. Also, diclofenac appears to reduce free intracellular arachidonic concentrations in leukocytes by changing the release or extraction of these fatty acids (Gilman, 2012).

The interactions that occur between COX-2 and diclofenac are steric interactions. Steric interactions occur between diclofenac with amino acids Leu 390, Trp 387, Glu 203, His 388, His 207, and Thr 206. The interaction parameters between $\mathrm{COX}-2$ and diclofenac obtained $\Delta G$ values of $-7.843 \mathrm{kcal} / \mathrm{mol}$ and RMSD values of $2.07851 \AA$. The RMSD value of COX2-diclofenac complex obtained $\geq 2$, which indicates that the copy ligand position is not similar to the native ligand. Also, several parameters were obtained using PatchDock, namely $\Delta G$ of $-55.22 \mathrm{kcal} /$ mol, attractive VdW of -21.47 , and repulsive $\mathrm{VdW}$ of 3.95. Diclofenac compounds interact with six amino acid residues from the COX-2 receptor so that it can be predicted that diclofenac can inhibit COX-2, which disrupts the conversion of arachidonic to prostaglandin (PGG2).

\section{CONCLUSION}

Interactions that occur between COX-2 and indomethacin are interactions of hydrogen and steric interactions. Hydrogen interactions connect between indomethacin and amino acid Leu 531, while steric interactions link between indomethacin and Trp 387, Tyr 385, Tyr 355, Leu 352, and Val 523. Interactions that occur between COX-2 and diclofenac are steric interactions between diclofenac and amino acids Leu 390, $\operatorname{Trp} 387, \mathrm{Gln} 203$, His 388, His 207, and Thr 206.

\section{REFERENCE}

Chandrasoma, P., \& Taylor, C. R. (2005). Ringkasan Patologi Anatomi. Jakarta, Indonesia: Penerbit Buku Kedokteran EGC.

Gilman, A. G. (2012). Goodman \& Gilman Dasar Farmakologi Terapi Edisi 10. Jakarta, Indonesia: Penerbit Buku Kedokteran EGC.

Kulmacz, R. J., van der Donk, W. A., \& Tsai, A. L. (2003). Comparison of The Properties of Prostaglandin H Synthase-1 and -2. Progress in Lipid Research, 42(5), 377-404.

Kumar, V., Coltran, R. S., \& Robbins, S. L. (2012). Robbins Buku Ajar Patologi Edisi 7 Volume 2. Jakarta, Indonesia: Penerbit Buku Kedokteran EGC.

McDonald, B. (2016). Stoelting's Pharmacology \& Physiology in Anesthetic Practice-5 th Edition. Canadian Journal of Anesthesia/ Journal canadien d'anesthésie, 63(3), 370-371.

Rouzer, C. A., \& Marnett, L. J. (2003). Mechanism of Free Radical Oxygenation of Polyunsaturated Fatty Acids by Cyclooxygenases. Chemical Reviews, 103(6), 2239-2304. 
Rouzer, C. A., \& Marnett, L. J. (2009). Cyclooxygenases: Structural and Functional Insights. Journal of Lipid Research, 50 (Supplement), S29-S34.

Serhan, C. N., \& Oliw, E. (2001). Unorthodox Routes to Prostanoid Formation: New Twists in Cyclooxygenase-Initiated Pathways. The Journal of Clinical Investigation, 107(12), 14811489.

Wilmana, P. F., \& Gunawan, S, G. (2012). AnalgesikAntipiretik Analgesik Anti-Inflamasi Nonsteroid dan Obat Gangguan Sendi Lainnya. In S. G. Gunawan (Ed.), Farmakologi dan Terapi Edisi 5 (Cetak ulang dengan Tambahan, 2012) (pp. 230-246). Jakarta, Indonesia: Badan Penerbit FKUI. 